\title{
International Conference Combines Hydrogen Effects on Material Behavior and Corrosion Deformation Interactions, September 2002
}

It is well recognized that the interactions between hydrogen, corrosion, and deformation control the degradation and failure of materials in many diverse service and processing environments. Five previous international conferences in the United States on "Hydrogen Effects on Material Behavior" and two in Europe on "Corrosion Deformation Interactions" attest to their importance. These conferences now join together to provide a common forum for discussion of the latest advances in each field and to establish a basis for continued research in the new century.

This international conference will be held September 22-26, 2002, at Jackson Lake Lodge in Grand Teton National Park (www.gtlc.com) in Moran, Wyoming. This is the same location as four previous conferences on hydrogen effects, and the lodge is noted for its fine conference facilities, modern accommodations, and informal character. The conference is sponsored by the Joint TMS/ASM Environmental Effects Committee, Structural Materials Division, TMS Environment Sensitive Fracture Working Group, and the European Federation of Corrosion. It is endorsed by the Materials Research Society.

The technical program will consist of invited and submitted papers and posters presented at morning and evening sessions. This format will avoid simultaneous sessions and leave the afternoons free for workshops, informal contact with attendees, and recreation. Topics will include the effects of hydrogen, deuterium, or tritium on the mechanical and physical properties of materials; hydrogen transport and mechanisms; hydrogen-induced crack growth; the effects of corrosion on plasticity; the effects of deformation on stress corrosion cracking and corrosion fatigue; the effects of hydrogen and corrosion on fracture modes; mechanisms con- trolling degradation; and engineering applications. Special emphasis will be given to experimental and theoretical modeling in all topic areas.

A proceedings is planned with no differentiation between oral and poster session papers. Those interested in presenting or attending are encouraged to access the conference Web site (www.ca.sandia.gov/ jacksonconference) or contact one of the conference chairs: Neville Moody, Sandia National Laboratories, tel. 925-294-2622, e-mail nrmoody@sandia.gov; Anthony Thompson, Lawrence Berkeley Laboratory, tel. 510-486-7021, e-mail awthompson@ lbl.gov; Richard Ricker, National Institute of Standards and Technology, tel. 301-975-6023, e-mail richard.ricker@nist.gov; Gary Was, University of Michigan, tel. 734-763-4675, e-mail gsw@umich.edu; or Thierry Magnin, Ecole des Mines de St. Etienne, tel. 33-04-7742-01-95, e-mail magnin@emse.fr.

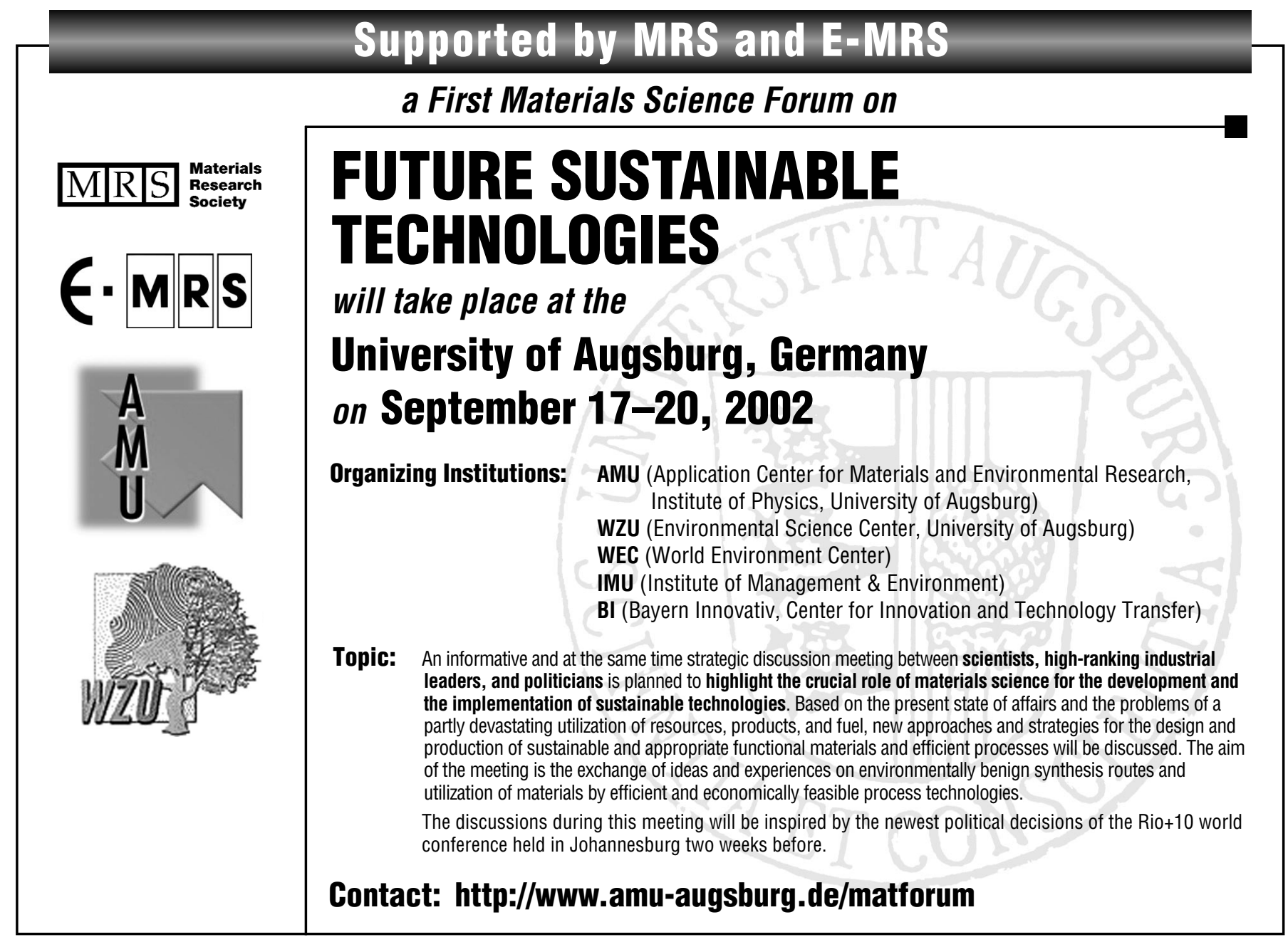

